\title{
Ação gênica, heterose e depressão endogâmica de caracteres de produção em linhagens mutantes de algodoeiro herbáceo(1)
}

\author{
Cândida Hermínia Campos de Magalhães Bertini(2), Fanuel Pereira da Silva( ${ }^{(2)}$, Raimundo de Pontes Nunes ${ }^{(2)}$ \\ e José Higino Ribeiro dos Santos ${ }^{(2)}$
}

\begin{abstract}
Resumo - Este trabalho teve por objetivo estimar parâmetros hereditários no algodoeiro herbáceo (Gossypium hirsutum L.) a partir de análise genética convencional envolvendo dois progenitores e as gerações $\mathrm{F}_{1}, \mathrm{~F}_{2}, \mathrm{RC}_{1}$ e $\mathrm{RC}_{2}$. A ação gênica, a heterose e a depressão endogâmica foram calculadas em relação aos caracteres número de dias para a floração, número de capulhos, peso do capulho, produção de algodão em caroço, porcentagem de fibra, e peso de 100 sementes. Os valores de herdabilidade no sentido restrito variaram de $2,27 \%$, em peso médio de capulho, a $67,57 \%$, em porcentagem de fibra. A ação gênica de natureza dominante predominou em número de dias para a floração, número de capulhos, peso médio do capulho, produção de algodão em caroço e fibra. Os valores heteróticos calculados variaram de $-0,77 \%$, em número de dias para a floração, a $96,41 \%$, na produção de fibra. Depressão endogâmica estatisticamente significativa foi obtida em peso médio de capulho e porcentagem de fibra. A presença de ação gênica aditiva sugere que avanços genéticos podem ser alcançados por meio dos métodos comuns de seleção, enquanto a predominância de ação dominante ou epistática indica a necessidade do uso de variedades híbridas ou outros métodos que aproveitem este tipo de variabilidade genética.
\end{abstract}

Termos para indexação: Gossypium hirsutum, seleção, híbridos, herdabilidade.

\section{Gene action, heterosis and inbreeding depression of yield characters in mutant lines of upland cotton}

\begin{abstract}
The objective of this study was to estimate the heredity parameters in hybrids of upland cotton (Gossypium hirsutum L.) obtained from a conventional genetic analysis involving two parental lines and including the $\mathrm{F}_{1}, \mathrm{~F}_{2}, \mathrm{RC}_{1}$, and $\mathrm{RC}_{2}$ generations. The gene action, heterosis and inbreeding depression were calculated for the characters days to first flower initiation, number of bolls, boll weight, fiber percent, fiber yield and weight of 100 seeds. Narrow-sense heritability ranged from $2.27 \%$ for boll weight to $67.57 \%$ for fiber percent. The dominance effect was the most important to days to first flower initiation, number of bolls, boll weight, and fiber yield, while the additive effect was the most important for fiber percent and weight of 100 seeds. Heterotic effects of $96.41 \%$ was obtained for fiber yield and of $-0.77 \%$ for days to first flower initiation. Inbreeding depression was detected only for boll weight and fiber percent. The presence of large amount of additive effects suggests that there is a potential for obtaining further yield gains and fiber property improvements without resorting to the use of hybrids. On the other hand, significant dominance deviations indicated that breeding for hybrids varieties would result in improvement over existing ones.
\end{abstract}

Index terms: Gossypium hirsutum, selection, hybrids, heritability.

(1) Aceito para publicação em 25 de agosto de 2000 .

Extraído da Dissertação de Mestrado apresentada pelo primeiro autor à Universidade Federal do Ceará (UFC), Fortaleza, CE. Financiado pela CAPES

(2) UFC, Centro de Ciências Agrárias (CCA), Dep. de Fitotecnia, Caixa Postal 12168, CEP 60455-740 Fortaleza, CE. E-mail: chcmbertini@bol.com.br, fanuel@ufc.br, pontes@ufc.br, jhr@secrel.com.br

\section{Introdução}

Os estudos dos parâmetros hereditários, assim como a heterose e a depressão endogâmica, são de fundamental importância para o melhorista, pois proporcionam os conhecimentos básicos relacionados à genética quantitativa, os quais, por sua vez, 
viabilizam a disponibilização de materiais vegetais para serem utilizados em programas de melhoramento genético.

O conhecimento da contribuição dos componentes de variância é de grande importância para o melhorista, uma vez que a variabilidade fenotípica é o resultado da ação conjunta dos efeitos genéticos e de ambiente. A proporção desses efeitos em relação à variância fenotípica total orienta o melhorista na escolha do método de melhoramento mais vantajoso, e ao mesmo tempo facilita as predições dos ganhos de seleção.

As ações gênicas encontradas nas características de produção do algodoeiro herbáceo (Gossypium hirsutum L.) foram estudadas por vários autores, entre os quais destacam-se Al-Kawi \& Kohel (1969), Meredith Junior \& Bridge (1972), Gad et al. (1974) e Costa Neto (1985). Estes trabalhos mostraram que não havia uma definição consistente dos tipos de ações gênicas das características agronômicas estudadas.

Valores heteróticos variando de $18 \%$ a $35 \%$ foram obtidos por Miller \& Lee (1964). Hawkins et al. (1965) encontraram valor heterótico de $24 \%$ e vários de seus híbridos foram significativamente mais produtivos do que o melhor progenitor. Os valores heteróticos registrados nesses trabalhos foram de alta magnitude, principalmente quanto às características produção, número de capulhos e tamanho do capulho.

Plantas de algodoeiro herbáceo com características morfológicas alternativas, tais como folha okra, bráctea frego e cor vermelha da planta, oferecem vantagens relacionadas à redução das lesões provocadas por inseto-praga (Jones, 1972; Wilson $\&$ George, 1982). Além disso, algodoeiros com folha okra ainda apresentam maior precocidade, maior produção de flores, melhor penetração de inseticidas, e reduzida incidência de maçãs apodrecidas, em comparação com algodoeiros de folha normal (Jones et al., 1980; Jones, 1982; Heitholt, 1993; Silva et al., 1996; Heitholt \& Meredith Junior, 1998). Entretanto, esses mutantes morfológicos não têm sido utilizados na produção de novas cultivares.

O objetivo deste trabalho foi estudar a ação gênica, a heterose e a depressão endogâmica em populações híbridas de algodoeiro herbáceo envolvendo três mutantes morfológicos, com a finalidade de caracterizá-los quantitativamente segundo os seus parâmetros hereditários.

\section{Material e Métodos}

Dez populações foram obtidas a partir do cruzamento realizado entre duas linhagens portadoras de mutantes morfológicos. A primeira linhagem continha as mutações bráctea frego e folha okra (BFFO) e foi obtida a partir do cruzamento entre uma linhagem mutante bráctea frego encontrada em um campo comercial de algodoeiro herbáceo, em Patos, PB, e uma cultivar americana, Stoneville 7-A, que continha a folha okra. A segunda é oriunda da EmbrapaCentro Nacional de Pesquisa de Algodão, Campina Grande, $\mathrm{PB}$, e foi introduzida dos Estados Unidos da América, com o nome de planta vermelha (PV), pois todas as suas partes contêm cores avermelhadas.

Os progenitores, $\mathrm{BFFO}$ e $\mathrm{PV}$, foram cruzados reciprocamente no ano de 1995 , e as gerações $\mathrm{P}_{1}, \mathrm{P}_{2}, \mathrm{~F}_{1}, \mathrm{~F}_{1}^{\prime}, \mathrm{F}_{2}$, $\mathrm{F}_{2}{ }_{2}$ e retrocruzamentos dos progenitores $\mathrm{RC}_{1}$ e $\mathrm{RC}^{\prime}{ }_{1} \mathrm{e}$ $\mathrm{RC}_{2}$ e $\mathrm{RC}_{2}$ foram plantados no ano de 1997, em área experimental do Centro de Ciências Agrárias da Universidade Federal do Ceará. O experimento foi instalado sob regime de irrigação, e media $39 \mathrm{~m}$ de comprimento x $15 \mathrm{~m}$ de largura. O plantio recebeu as adubações e tratamentos fitossanitários recomendados para a cultura.

O delineamento experimental utilizado foi o de blocos ao acaso, com duas repetições e onze tratamentos correspondentes às dez populações obtidas $\left(\mathrm{P}_{1}, \mathrm{P}_{2}, \mathrm{~F}_{1}, \mathrm{~F}_{1}{ }_{1}\right.$, $\mathrm{F}_{2}, \mathrm{~F}^{\prime}{ }_{2}, \mathrm{RC}_{1}, \mathrm{RC}^{\prime}{ }_{1}, \mathrm{RC}_{2} \mathrm{e} \mathrm{RC}^{\prime}{ }_{2}$ ), mais a cultivar CNPA-7H, utilizada como testemunha. A parcela experimental foi representada por uma fileira simples de $15 \mathrm{~m}$ de comprimento. $\mathrm{O}$ espaçamento adotado foi de $0,80 \mathrm{~m}$ entre fileiras e $0,20 \mathrm{~m}$ entre plantas, com duas plantas por cova.

Os genótipos das populações segregantes foram identificados com relação às características morfológicas folha okra $\left(\mathrm{L}_{2}{ }^{0}\right)$, folha normal $\left(\mathrm{l}_{2}\right)$, bráctea normal $\left(\mathrm{F}_{\mathrm{g}}\right)$, bráctea frego $\left(f_{g}\right)$, cor vermelha da planta $\left(R_{1}\right)$ e cor verde $\left(r_{1}\right)$. Os dados coletados, pertinentes aos caracteres agronômi$\cos$, foram: número de dias para a floração, número de capulhos, peso do capulho, produção de algodão em caroço, produção de fibras, porcentagem de fibras e peso de 100 sementes.

Os cálculos das estimativas dos parâmetros hereditários e ações gênicas foram feitos com o auxílio do programa GENES (Cruz, 1997). O modelo utilizado para calcular as ações gênicas foi o proposto por Mather \& Jinks (1984). Também foram calculados os valores heteróticos e de depressão endogâmica segundo as fórmulas de Shull (1952) e El-Fawal et al. (1978), respectivamente. 


\section{Resultados e Discussão}

\section{Componentes de variância e herdabilidades}

A Tabela 1 contém as estimativas dos componentes de variâncias fenotípica, ambiental, genotípica, aditiva e dominante, as herdabilidades e o grau médio de dominância das características agronômicas estudadas no cruzamento envolvendo duas linhagens mutantes de algodoeiro herbáceo. A variância de natureza genética representou a maior porção da variância fenotípica total em quase todas as características agronômicas estudadas, exceto no que diz respeito aos caracteres peso médio do capulho e peso de 100 sementes. As porcentagens das variâncias genéticas com relação às fenotípicas corresponderam a $6 \%$ no peso médio de capulho, $84 \%$ na produção de algodão em caroço e produção de fibra, $73 \%$ na porcentagem de fibra, e $35 \%$ no peso de 100 sementes. O componente de variância genotípica mais importante foi o de natureza aditiva nos caracteres produção de algodão em caroço (51\%), porcentagem de fibra $(92 \%)$ e peso de 100 sementes ( $87 \%)$, enquanto o de natureza dominante predominou nos caracteres número de dias para a floração $(55 \%)$, número de capulhos (75\%), peso médio do capulho $(75 \%)$ e produção de fibra ( $56 \%$ ).

A comparação dos resultados obtidos neste estudo com os publicados por Marani (1964) mostra algumas semelhanças. Esse autor concluiu que o componente mais importante da variância genética na produção e em seus componentes foi o do tipo aditivo, embora variâncias genéticas de natureza dominante tenham sido detectadas. Como a variância genética aditiva é a responsável pela determinação do valor reprodutivo, pode-se dizer que quanto maior for o valor desta, melhores resultados serão conseguidos no momento da seleção de indivíduos visando ao caráter em consideração.

A análise da Tabela 1 mostra que somente as características número de dias para a floração, porcentagem de fibra e peso de 100 sementes apresentaram dominância parcial negativa em direção ao progenitor PV; os demais caracteres se situaram fora dos limites abrangidos pelos progenitores, isto é, apresentaram sobredominância. O número de capulhos foi o único caráter a apresentar valor positivo de sobredominância. Vale salientar que quando se utiliza a média para inferir sobre os tipos de ações gênicas, o que se obtém é uma soma algébrica de cada um dos locos individualmente, e pode ocorrer que os genes dominantes estejam presentes, porém atuando em sentidos opostos nos vários locos, o que pode conduzir a um efeito final pequeno ou nulo, e dar, indiretamente, uma idéia errônea do que realmente ocorre (Mather \& Jinks, 1984).

Com relação à herdabilidade no sentido amplo, constataram-se valores elevados em quase todas as características agronômicas, exceto no peso médio do capulho e peso de 100 sementes. Estes valores variaram de $6,32 \%$ no peso médio do capulho, a $89,06 \%$ no número de capulhos. Com relação à herdabilidade no sentido restrito, estes valores variaram de $2,27 \%$ no peso médio de capulhos a $67,57 \%$

Tabela 1. Estimativas dos componentes de variâncias fenotípica $\left(\mathrm{S}_{\mathrm{F}}{ }^{2}\right)$, ambiental $\left(\mathrm{S}_{\mathrm{E}}{ }^{2}\right)$, genotípica $\left(\mathrm{S}_{\mathrm{G}}{ }^{2}\right)$, aditiva $\left(\mathrm{S}_{\mathrm{A}}{ }^{2}\right)$, dominante $\left(\mathrm{S}_{\mathrm{D}}{ }^{2}\right)$; herdabilidades no sentido amplo $\left(\mathrm{h}_{\mathrm{a}}{ }^{2}\right)$ e restrito $\left(\mathrm{h}_{\mathrm{r}}{ }^{2}\right)$ e grau médio de dominância (GMD) das características agronômicas estudadas no cruzamento envolvendo linhagens mutantes de algodoeiro herbáceo. Fortaleza, CE, 1999.

\begin{tabular}{ccccccrc}
\hline $\begin{array}{c}\text { Variâncias e } \\
\text { parâmetros } \\
\text { hereditários }\end{array}$ & $\begin{array}{c}\mathrm{N}^{\mathrm{o}} \text { de dias } \\
\text { para a } \\
\text { floração }\end{array}$ & $\begin{array}{c}\mathrm{N}^{\mathrm{o}} \text { de } \\
\text { capulhos }\end{array}$ & $\begin{array}{c}\text { Peso médio } \\
\text { do } \\
\text { capulho }\end{array}$ & $\begin{array}{c}\text { Produção } \\
\text { total }\end{array}$ & $\begin{array}{c}\text { Produção } \\
\text { de } \\
\text { fibra }\end{array}$ & $\begin{array}{c}\text { Fibra } \\
(\%)\end{array}$ & $\begin{array}{c}\text { Peso de } \\
100 \\
\text { sementes }\end{array}$ \\
\hline $\mathrm{S}_{\mathrm{F}}{ }^{2}$ & 23,70 & 30,23 & 0,66 & 553,00 & 69,33 & 18,92 & 0,93 \\
$\mathrm{~S}_{\mathrm{E}}{ }^{2}$ & 9,04 & 3,31 & 0,62 & 90,82 & 11,10 & 5,10 & 0,60 \\
$\mathrm{~S}_{\mathrm{G}}{ }^{2}$ & 14,66 & 26,93 & 0,04 & 462,18 & 58,23 & 13,82 & 0,32 \\
$\mathrm{~S}_{\mathrm{A}}{ }^{2}$ & 6,65 & 6,77 & 0,01 & 234,71 & 25,35 & 12,78 & 0,28 \\
$\mathrm{~S}_{\mathrm{D}}{ }^{2}$ & 8,01 & 20,15 & 0,03 & 227,47 & 32,88 & 1,04 & 0,04 \\
$\mathrm{~h}_{\mathrm{a}}{ }^{2}$ & 61,87 & 89,06 & 6,32 & 83,58 & 83,57 & 73,05 & 34,84 \\
$\mathrm{~h}_{\mathrm{r}}{ }_{\mathrm{GMD}}$ & 28,05 & 22,40 & 2,27 & 42,44 & 36,57 & 67,57 & 30,56 \\
\hline
\end{tabular}


na porcentagem da fibra. Valores de herdabilidade no sentido amplo mais elevados, relativos às referidas características, indicam maiores influências dos efeitos não-aditivos e ambientais.

Os dados encontrados na literatura também mostram herdabilidades elevadas com relação às características agronômicas. Al-Jibouri et al. (1958) encontraram herdabilidades, no sentido amplo, da ordem de $0,59,0,90,0,77$ e 0,87 relativos à produção, porcentagem de fibra, peso do capulho e peso de 100 sementes, respectivamente. Miller et al. (1958) encontraram valores semelhantes aos dos autores supracitados, relativos à porcentagem de fibra e ao peso de 100 sementes, embora a produção e o peso do capulho tenham mostrado valores de 0,66 e 0,51 , respectivamente. Os valores de herdabilidades baixos, observados neste trabalho, talvez possam ser explicados pela pouca diferença detectada entre os progenitores quanto às características mencionadas. De fato, o desvio-padrão da média na geração $\mathrm{F}_{2} \mathrm{com}$ relação à característica peso médio do capulho foi de

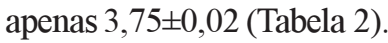

\section{Ação gênica}

Das sete características agronômicas estudadas, somente número de dias para a floração, porcenta- gem de fibra e peso de 100 sementes apresentaram médias na geração $F_{1}$ dentro dos limites dos progenitores, ocorrendo tendências de dominâncias parciais das três características no sentido do progenitor planta vermelha (Tabela 2). A produção de algodão em caroço, a produção de fibra, o número de capulhos e o peso médio do capulho da geração $F_{1}$ mostraram médias fora dos limites parentais, caracterizando heterose. As gerações de retrocruzamentos $\mathrm{RC}_{1}$, com $75 \%$ do genoma do progenitor BFFO, e de $\mathrm{RC}_{2}$, com $75 \%$ do genoma do $\mathrm{PV}$, apresentaram médias direcionadas aos seus respectivos progenitores com relação a quase todas as características.

Os resultados dos testes de homogeneidade das variâncias (teste $F$ ) e testes de comparações das médias (teste $t$ ), calculados entre os progenitores $P_{1}$ (PV) e $\mathrm{P}_{2}$ (BFFO) e entre cada progenitor e a cultivar CNPA-7H, mostraram que somente o número de capulhos não apresentou diferenças significativas entre as médias dos progenitores (Tabela 3). Observou-se que o progenitor PV apresentou os valores mais elevados de produção de algodão em caroço, produção de fibra, peso médio do capulho, porcentagem de fibra e peso de 100 sementes, em comparação com o progenitor BFFO. No entanto, quando foram comparados os progenitores com a cultivar

Tabela 2. Médias e erro-padrão das médias dos progenitores $\mathrm{P}_{1}$, e $\mathrm{P}_{2}$, das populações $\mathrm{F}_{1}, \mathrm{~F}_{2}, \mathrm{RC}_{1}$ e $\mathrm{RC}$, resultantes do cruzamento envolvendo duas linhagens mutantes de algodoeiro herbáceo, e da cultivar CNPA-7H, utilizada como testemunha. Fortaleza, CE, 1999.

\begin{tabular}{lcccccrr}
\hline Populações & $\begin{array}{c}\mathrm{N}^{\mathrm{o}} \text { de dias para a } \\
\text { floração }\end{array}$ & $\begin{array}{c}\mathrm{N}^{\mathrm{o}} \text { de } \\
\text { capulhos }\end{array}$ & $\begin{array}{c}\text { Peso médio } \\
\text { de capulho }(\mathrm{g})\end{array}$ & $\begin{array}{c}\text { Produção } \\
\text { total }(\mathrm{g})\end{array}$ & $\begin{array}{c}\text { Produção } \\
\text { de fibra }(\mathrm{g})\end{array}$ & $\begin{array}{c}\text { Fibra } \\
(\%)\end{array}$ & $\begin{array}{c}\text { Peso de 100 } \\
\text { sementes }(\mathrm{g})\end{array}$ \\
\hline $\mathrm{P}_{1}(\mathrm{BFFO})$ & $52,18 \pm 0,39$ & $5,93 \pm 0,17$ & $2,57 \pm 0,06$ & $14,83 \pm 0,52$ & $4,55 \pm 0,14$ & $31,18 \pm 0,32$ & $8,68 \pm 0,19$ \\
$\mathrm{P}_{2}(\mathrm{PV})$ & $47,08 \pm 0,24$ & $5,68 \pm 0,19$ & $4,14 \pm 0,10$ & $23,04 \pm 0,98$ & $7,93 \pm 0,33$ & $36,23 \pm 0,25$ & $10,28 \pm 0,25$ \\
$\mathrm{~F}_{1}$ & $49,25 \pm 0,27$ & $8,44 \pm 0,18$ & $4,20 \pm 0,08$ & $34,15 \pm 1,06$ & $12,26 \pm 0,38$ & $35,89 \pm 0,18$ & $9,63 \pm 0,27$ \\
$\mathrm{~F}_{2}$ & $51,28 \pm 0,13$ & $9,39 \pm 0,15$ & $3,75 \pm 0,02$ & $35,67 \pm 0,63$ & $12,53 \pm 0,22$ & $35,15 \pm 0,12$ & $9,56 \pm 0,31$ \\
$\mathrm{RC}_{1}$ & $52,12 \pm 0,26$ & $9,67 \pm 0,28$ & $3,43 \pm 0,04$ & $32,48 \pm 1,02$ & $11,02 \pm 0,36$ & $33,29 \pm 0,21$ & $9,41 \pm 0,27$ \\
$\mathrm{RC}_{2}$ & $42,88 \pm 0,20$ & $9,81 \pm 0,26$ & $4,41 \pm 0,04$ & $41,67 \pm 1,14$ & $15,15 \pm 0,42$ & $36,33 \pm 0,16$ & $10,35 \pm 0,29$ \\
$\mathrm{CNPA-7H}$ & $47,43 \pm 0,38$ & $7,35 \pm 0,32$ & $5,91 \pm 0,12$ & $41,54 \pm 1,82$ & $16,09 \pm 0,69$ & $39,07 \pm 0,27$ & $12,10 \pm 0,12$ \\
\hline
\end{tabular}

Tabela 3. Teste de homogeneidade das variâncias (teste F) e teste de comparação das médias (teste t) das características agronômicas dos progenitores $\mathrm{P}_{1}$ (bráctea frego, folha okra) e $\mathrm{P}_{2}$ (planta vermelha) e dos progenitores e da cultivar CNPA-7H. Fortaleza, CE, 1999.

\begin{tabular}{|c|c|c|c|c|c|c|c|c|c|c|c|c|c|c|}
\hline \multirow[t]{2}{*}{$\begin{array}{l}\text { Compa- } \\
\text { rações }\end{array}$} & \multicolumn{2}{|c|}{$\begin{array}{l}\mathrm{N}^{\mathrm{o}} \text { de dias para a } \\
\text { floração }\end{array}$} & \multicolumn{2}{|c|}{$\begin{array}{c}\mathrm{N}^{\mathrm{o}} \mathrm{de} \\
\text { capulhos }\end{array}$} & \multicolumn{2}{|c|}{$\begin{array}{l}\text { Peso médio } \\
\text { do capulho }\end{array}$} & \multicolumn{2}{|c|}{$\begin{array}{l}\text { Produção } \\
\text { total }\end{array}$} & \multicolumn{2}{|c|}{$\begin{array}{c}\text { Produção } \\
\text { de fibra }\end{array}$} & \multicolumn{2}{|c|}{$\begin{array}{c}\text { Fibra } \\
(\%)\end{array}$} & \multicolumn{2}{|c|}{$\begin{array}{c}\text { Peso de } 100 \\
\text { sementes }\end{array}$} \\
\hline & $\mathrm{F}$ & $\mathrm{t}$ & $\mathrm{F}$ & $\mathrm{t}$ & $\mathrm{F}$ & $\mathrm{t}$ & $\mathrm{F}$ & $\mathrm{t}$ & $\mathrm{F}$ & $\mathrm{t}$ & $\mathrm{F}$ & $\mathrm{t}$ & $\mathrm{F}$ & $\mathrm{t}$ \\
\hline$\overline{P_{1} \text { vs. } P_{2}}$ & $2,21 *$ & $10,98^{*}$ & 1,37 & 0,96 & $2,39^{*}$ & $-13,08^{*}$ & $3,57 *$ & $-7,40^{*}$ & $5,05^{*}$ & $-9,39 *$ & $1,67^{*}$ & $-12,32^{*}$ & $1,94 *$ & $-4,03 *$ \\
\hline $\mathrm{P}_{1}$ vs. CNPA-7H & 1,31 & $8,45^{* *}$ & $4,00^{*}$ & $-3,95^{*}$ & $4,06^{*}$ & $-25,21 *$ & $13,19 *$ & $-14,13^{*}$ & $24,11^{*}$ & $-16,25^{*}$ & 1,26 & $-18,78^{* *}$ & $3,58^{*}$ & $-4,43 *$ \\
\hline $\mathrm{P}_{2}$ vs. CNPA-7H & $2,90^{*}$ & $-0,77$ & $2,91 *$ & $-4,39 *$ & 1,43 & $-11,52 * *$ & $3,70^{*}$ & $-8,98^{*}$ & $4,76^{*}$ & $-10,74^{*}$ & 1,32 & $-7,67 * *$ & $1,85^{*}$ & $-2,13^{*}$ \\
\hline
\end{tabular}


CNPA-7H, esta mostrou-se bastante superior às linhagens parentais.

A comparação dos resultados obtidos neste estudo com os encontrados na literatura mostra semelhança. Em vários trabalhos, algodoeiros com folha okra apresentaram produtividades menores do que algodoeiros com folha normal (Jones, 1982; Wilson \& George, 1982; Meredith Junior \& Wells, 1986; Silva et al., 1996). O caráter cor vermelha também foi associado a uma redução na produção, em comparação com cor verde (Jones, 1972). Neste estudo, a linhagem contendo folha okra, bráctea frego e cor verde apresentou menor produção de algodão em caroço (14,83 g/planta vs. 23,04, um decréscimo de $35,63 \%)$ e menor produção de fibra $(4,55 \mathrm{~g} /$ planta vs. 7,93, um decréscimo de $42,62 \%$ ) em comparação com a linhagem com folha normal, bráctea normal e cor vermelha. Estas mesmas observações podem ser encontradas na literatura que identifica reduções nas produtividades quando os caracteres folha okra e bráctea frego estão associados (Wilson \& George, 1982).

Uma das vantagens dos algodoeiros com folha okra é sua maior precocidade (Wilson \& George, 1982). No entanto, o progenitor planta vermelha (PV) mostrou-se mais precoce do que o bráctea frego, folha okra (BFFO), considerando-se o número de dias para o aparecimento da primeira flor $(47,08$ vs. 52,18, Tabela 2). Dados encontrados na literatura também registram atraso na data de floração, perda na precocidade, redução no tamanho do capulho e na porcentagem de fibra, associados com o caráter bráctea frego. Por outro lado, os dados comparativos de Silva et al. (1996) entre isolinhas de algodão com folha okra e folha normal, com diferentes padrões genéticos, não identificaram diferenças significativas nestas isolinhas quando o critério usado para medir precocidade foi o número de dias para o aparecimento da primeira flor.

A análise dos dados contidos na Tabela 4 mostra, em relação ao caráter número de dias para a floração, um valor baixo de ação gênica dominante, embora estatisticamente significativo. Com relação às características produção de algodão em caroço, produção de fibra e peso médio de capulho, foram verificadas significâncias nas ações gênicas aditiva, dominante e epistática; a ação gênica de natureza dominante predominou sobre as demais, já que esta apresentou maior valor positivo. Os caracteres porcentagem de fibra e peso de 100 sementes revelaram ações gênicas de natureza aditiva significativas, enquanto o número de capulhos mostrou ação gênica dominante significativa.

Os estudos de Meredith Junior \& Bridge (1972) mostraram predominância da ação gênica aditiva nos caracteres porcentagem de fibra e peso de 100 sementes, no G. hirsutum. Al-Kawi \& Kohel (1969), em estudos com G. hirsutum, indicaram a predominância da ação gênica de natureza dominante ou epistática em todas as características agronômicas estudadas. Virusparkshappa et al. (1978) também encontraram que o efeito gênico aditivo foi significativo no número de capulhos, em dois dos seis cruzamentos estudados; nos demais houve predominância dos efeitos dominante e dominante $\mathrm{x}$ dominante. No entanto, em peso do capulho o efeito dominante apresentou maior valor positivo do que o aditivo. Efeitos epistáticos foram observados nos

Tabela 4. Tipos de ação gênica das gerações $\mathrm{P}_{1}, \mathrm{P}_{2}, \mathrm{~F}_{1}, \mathrm{~F}_{2}, \mathrm{RC}_{1}$ e $\mathrm{RC}$, relativa às características agronômicas estudadas no cruzamento envolvendo duas linhagens mutantes de algodoeiro herbáceo. Fortaleza, CE, 1999.

\begin{tabular}{cccccccc}
\hline $\begin{array}{l}\text { Ação } \\
\text { gênica }\end{array}$ & $\begin{array}{c}\mathrm{N}^{\text {o }} \text { de dias para } \\
\text { a floração }\end{array}$ & $\begin{array}{c}\mathrm{N}^{\mathrm{o}} \text { de } \\
\text { capulhos }\end{array}$ & $\begin{array}{c}\text { Peso médio } \\
\text { do capulho }\end{array}$ & $\begin{array}{c}\text { Produção } \\
\text { total }\end{array}$ & $\begin{array}{c}\text { Produção } \\
\text { de fibra }\end{array}$ & $\begin{array}{c}\text { Fibra } \\
(\%)\end{array}$ & $\begin{array}{c}\text { Peso de } \\
100 \text { sementes }\end{array}$ \\
\hline a & 2,55 & 0,13 & $-0,78^{* *}$ & $-4,10^{* *}$ & $-1,69^{* *}$ & $-2,52^{*}$ & $-0,80^{* *}$ \\
d & $0,44^{* *}$ & $15,92^{* *}$ & $2,72^{* *}$ & $68,59^{* *}$ & $25,82^{* *}$ & $-0,47$ & 4,06 \\
aa & $-2,70^{* *}$ & 1,41 & 0,66 & 5,63 & 2,22 & $-1,36$ & 1,30 \\
ad & $-0,62$ & $-0,54$ & $-0,38$ & $-10,17 * *$ & $-4,89 * *$ & $-1,02$ & $-0,29$ \\
dd & $-3,52$ & $-11,87 * *$ & $-1,22^{* *}$ & $-47,75^{* *}$ & $-17,57 * *$ & 1,30 & $-2,61$ \\
\hline
\end{tabular}

(1)a: ação gênica aditiva; d: ação gênica dominante; aa: ação gênica epistática do tipo aditivo $\mathrm{x}$ aditivo; ad: ação gênica epistática do tipo aditivo $\mathrm{x}$ dominante; dd: ação gênica epistática do tipo dominante x dominante. ${ }^{*} \mathrm{e}^{* *}$ Significativo a $5 \%$ e a $1 \%$ de probabilidade, respectivamente 
seis cruzamentos estudados. Costa Neto (1985) detectou ação gênica aditiva em peso de 100 sementes e ação gênica de natureza dominante no peso médio de capulho e na porcentagem de fibra. Os resultados deste estudo são muito próximos aos desses autores citados. Por outro lado, Bedair et al. (1953) encontraram variâncias de naturezas aditiva e dominante pertinente ao peso do capulho e ações gênicas de natureza aditiva e dominante não-significativas, com valores negativos ou iguais a zero, em peso de 100 sementes. Gad et al. (1974) registraram efeitos dominantes e epistáticos nas características peso do capulho e peso de 100 sementes, em cruzamentos interespecíficos de G. hirsutum x G. barbadense. No tocante à produção de fibra, os mesmos autores encontraram apenas efeitos gênicos aditivos, e quanto ao número de capulhos, foram observados efeitos aditivos, dominantes e epistáticos. Essas diferenças já eram esperadas em função das origens dos materiais genéticos utilizados.

Os efeitos gênicos que predominaram neste estudo foram o aditivo, em porcentagem de fibra e peso de 100 sementes, e o dominante, em número de dias para a floração, produção de algodão em caroço, produção de fibra, número de capulhos e peso médio do capulho. Nos casos de aditividades, supõe-se que a substituição de um alelo por outro tem sempre o mesmo efeito, independentemente da combinação gênica do outro loco. Isto é de grande importância para o melhoramento, pois a ação gênica aditiva é a única fixável diretamente.

\section{Heterose e depressão endogâmica}

A heterose relacionada com o número de dias para a floração foi negativa e igual a $-0,77 \%$ (Tabela 5).
Nos demais caracteres os valores heteróticos foram positivos e significativos, à exceção no peso de 100 sementes. Foram detectados valores heteróticos elevados $(+80,35 \%$ e $+96,41 \%)$ na produção de algodão em caroço e produção de fibra, enquanto no número de capulhos, peso médio do capulho, porcentagem de fibra e peso de 100 sementes, foram detectados valores intermediários e baixos, correspondentes a $+45,38 \%,+25,09 \%,+6,48 \% \mathrm{e}+1,55 \%$, respectivamente. Resultados semelhantes a estes foram encontrados por Miller \& Lee (1964). Costa Neto (1985) também encontrou valores heteróticos de magnitudes média, relativo a peso médio do capulho $(+16,95 \%)$, e baixa, relativos a porcentagem de fibra $(+1,41 \%)$ e peso de 100 sementes $(+9,94 \%)$. Ao contrário dos resultados obtidos neste estudo e pelos autores supracitados, Al-Kawi \& Kohel (1969) constataram valores heteróticos baixos relativos aos caracteres agronômicos avaliados em cruzamentos intraespecíficos na espécie G. hirsutum. Outros estudos encontrados na literatura relataram baixos valores heteróticos detectados em cruzamentos intraespecíficos. Fryxell et al. (1958), estudando o desempenho de híbridos de algodoeiro herbáceo, mostraram respostas heteróticas quanto à produção dos híbridos interespecíficos variando de $+21 \%$ a $+48 \%$, enquanto nos híbridos intraespecíficos, o maior valor registrado foi de $+19 \%$. Young \& Murray (1966) registraram valores heteróticos substanciais na produção dos híbridos das espécies G. arboreum e $G$. hirsutum; os valores encontrados, relativos à espécie diplóide, foram mais elevados do que os da espécie alotetraplóide. Por outro lado, Rao (1968)

Tabela 5. Valores heteróticos e de depressão endogâmica (DE) das características agronômicas estudadas no cruzamento envolvendo duas linhagens mutantes de algodoeiro herbáceo. Fortaleza, CE, 1999.

\begin{tabular}{lccccccc}
\hline Médias & $\begin{array}{c}\mathrm{N}^{\mathrm{o}} \text { de dias para } \\
\text { a floração }\end{array}$ & $\begin{array}{c}\mathrm{N}^{\mathrm{o}} \text { de } \\
\text { capulhos }\end{array}$ & $\begin{array}{c}\text { Peso médio } \\
\text { do capulho }\end{array}$ & $\begin{array}{c}\text { Produção } \\
\text { total }\end{array}$ & $\begin{array}{c}\text { Produção } \\
\text { de fibra }\end{array}$ & $\begin{array}{c}\text { Fibra } \\
(\%)\end{array}$ & $\begin{array}{c}\text { Peso de } \\
100 \text { sementes }\end{array}$ \\
\hline $\mathrm{P}_{1}$ & 52,18 & 5,93 & 2,57 & 14,83 & 4,55 & 31,18 & 8,68 \\
$\mathrm{P}_{2}$ & 47,08 & 5,68 & 4,14 & 23,04 & 7,93 & 36,23 & 10,28 \\
$\mathrm{P}_{\mathrm{m}}$ & 49,63 & 5,81 & 3,36 & 18,94 & 6,24 & 33,70 & 9,48 \\
$\mathrm{~F}_{1}$ & 49,25 & 8,44 & 4,20 & 34,15 & 12,26 & 35,89 & 9,63 \\
$\mathrm{~F}_{2}$ & 51,68 & 9,39 & 3,75 & 35,67 & 12,53 & 35,15 & 9,56 \\
\hline Heterose $(\%)$ & $-0,77^{\mathrm{ns}}$ & $+45,38^{*}$ & $+25,09^{* *}$ & $+80,35^{*}$ & $+96,41^{*}$ & $+6,48^{*}$ & $+1,55^{\mathrm{ns}}$ \\
$\mathrm{DE}(\%)$ & $-4,92^{*}$ & $-11,21^{*}$ & $+10,57^{* *}$ & $-4,44^{\text {ns }}$ & $-2,22^{\mathrm{ns}}$ & $+2,05^{*}$ & $+0,72^{\mathrm{ns}}$ \\
\hline${ }^{\text {ns }}$ & & & &
\end{tabular}


detectou níveis relativamente elevados de heterose, tanto em cruzamentos interespecíficos quanto nos intraespecíficos.

Quando se comparam os resultados deste estudo com os encontrados na literatura, observa-se que não há consistência nos valores obtidos. No entanto, há uma tendência para valores heteróticos superiores nos cruzamentos interespecíficos em comparação com os intraespecíficos. À luz dos conhecimentos da genética mendeliana, sabe-se que, quanto mais divergentes geneticamente são as linhagens, maiores respostas heteróticas podem ser observadas. Entretanto, a dificuldade para a utilização de híbridos originados de cruzamentos interespecíficos em caráter comercial prende-se à elevada esterilidade dos híbridos deste tipo.

Os dados deste estudo permitem inferir que entre os componentes de produção, o número de capulhos por planta foi o que mais contribuiu para a heterose. Resposta semelhante foi verificada por Al-Kawi \& Kohel (1969). Esta informação é importante para o melhoramento, no que diz respeito à seleção de indivíduos que tenham maiores números de capulhos por planta.

Com relação à depressão endogâmica, a análise da Tabela 5 mostra que o número de dias para a floração, produção de algodão em caroço, produção de fibra e número de capulhos, apresentaram valores negativos e iguais a $-4,92 \%,-4,44 \%,-2,22 \%$ e $-11,21 \%$, respectivamente, o que caracteriza a inexistência de endogamia. O peso médio do capulho, a porcentagem de fibra e o peso de 100 sementes, mostraram valores positivos da ordem de $+10,57 \%$, $+2,05 \%$ e $+0,72 \%$, respectivamente, e somente os dois primeiros são significativos. Virusparkshappa et al. (1978) encontraram valores de depressão endogâmica iguais a $+43,55 \% \mathrm{e}+24,08 \%$, relacionados a número de capulhos e peso médio do capulho, em híbridos da espécie $G$. hirsutum. Costa Neto (1985) evidenciou valores positivos iguais a $+15,13 \%$, $+5,28 \% \mathrm{e}+7,89 \%$ relativos a peso médio do capulho, porcentagem de fibra, e peso de 100 sementes.

Um dos grandes problemas para o melhorista que trabalha com híbridos é o declínio do vigor, acompanhado da redução da produtividade. Estas reduções em vigor e produtividade podem estar associadas a características morfológicas, agronômicas ou fisiológicas.
A presença de grandes quantidades de efeitos aditivos sugere que avanços adicionais na produtividade poderiam ser obtidos sem a necessidade de se recorrer ao uso de variedades híbridas de primeira geração. Entretanto, neste estudo, a presença de efeitos dominantes significativos, relativos à maioria dos caracteres agronômicos estudados, indica que um programa de melhoramento direcionado para variedades híbridas seria mais apropriado do que os métodos convencionais de obtenção de variedades. Segundo Meredith Junior \& Bridge (1972), o fator limitante na produção de variedades híbridas é a presença de insetos polinizadores em baixa quantidade, insuficiente para assegurar uma polinização adequada.

\section{Conclusões}

1. Avanços genéticos por meio de seleção podem ser alcançados na característica porcentagem de fibra.

2. Avanços genéticos pela utilização de híbridos de primeira geração podem ser alcançados nas demais características estudadas.

\section{Referências}

AL-JIBOURI, H. A.; MILLER, P. A.; ROBINSON, H. F. Genotypic and environmental variances and covariances in an upland cotton cross of interspecific origin. Agronomy Journal, Madison, v. 50, p. 623-636, 1958.

AL-KAWI, K. M.; KOHEL, R. J. Diallel analysis of yield and other agronomic characters in Gossypium hirsutum L. Crop Science, Madison, v. 9, p. 779-783, 1969.

BEDAIR, F. A.; BISHR, M. A.; ABDEL BARY, A. A.; EL-KHISHEN, A. A. Estimation of genetic variance for yield components in Egyptian cotton. Egyptian Journal of Genetics and Cytology, Giza, v. 2, p. 148-154, 1953.

COSTA NETO, F. V. Heterose, depressão endogâmica e ação gênica em cruzamento de algodão herbáceo, Gossypium hirsutum L. latifolium Hutch, e algodãomocó, Gossypium hirsutum L. r. marie galante Hutch. Fortaleza : UFC, 1985. 66 p. Dissertação de Mestrado.

CRUZ, C. D. Programa GENES: aplicativo computacional em genética e estatística. Viçosa : UFV, 1997. $442 \mathrm{p}$ 
EL-FAWAL, M. A.; BEDAIR, F. A.; BISHR, M. A.; HASSOUB, E. K. Manifestation of heterosis and combining ability in diallel crosses of Egyptian cotton. Egyptian Journal of Genetics and Cytology, Giza, v. 7 , p. $15-27,1978$.

FRYXELL, P. A.; STATEN, G.; PORTER, J. H Performance of some wide cross in Gossypium. Los Alamos : New Mexico Agricultural Experimental, 1958. p. 1-15. (New Mexico Agricultural Experimental Station Bulletin, 419)

GAD, A. M.; EL-FAWAL, M. A.; BISHR, M. A.; KRISHEN, A. A. Studies on gene action in an interspecific cross of cotton. I- Manifestations of types of genes effects. Egyptian Journal of Genetics and Cytology, Giza, v. 3, n. 1, p. 117-124, 1974.

HAWKINS, B. S.; PEACOCK, H. A.; BALLARD, W. W Heterosis and combining ability in upland cotton: effect on yield. Crop Science, Madison, v. 5, p. 543-546, 1965

HEITHOLT, J. J. Cotton boll retention and its relationship to lint yield. Crop Science, Madison, v. 33, p. 486-490, 1993

HEITHOLT, J. J.; MEREDITH JUNIOR, W. R. Yield, flowering, and leaf area index of okra-leaf and normal-leaf cotton isolines. Crop Science, Madison, v. 38, p. 643648,1998

JONES, J. E. Effect of the morphological characters of cotton on insects and pathogens. In: BELTWIDE COTTON RESEARCH CONFERENCE, 1972, Memphis. Proceedings... Memphis : National Cotton Council, 1972. p. 88-92.

JONES, J. E. The present state of art and science of cotton breeding for leaf-morphological types. In: BELTWIDE COTTON RESEARCH CONFERENCE, 1982, Las Vegas. Proceedings... Memphis : National Cotton Council, 1982. p. 93-97.

JONES, J. E.; BOWMAN, D. T.; BRAND, J. W.; PLAYLOFF, M. A. Effects of species cytoplasm and morphological traits on resistance to the boll weevil in upland cotton. In: BELTWIDE COTTON RESEARCH CONFERENCE, 1980, Memphis Proceedings.. Memphis : National Cotton Council, 1980. p. 286-287.

MARANI, A. Heterosis and combining ability for plant height and developmental data in a diallel cross of two species of cotton. Crop Science, Madison, v. 4, p. $265-$ 269,1964

MATHER, K.; JINKS, J. L. Introdução à genética biométrica. Ribeirão Preto : Sociedade Brasileira de Genética, 1984. 242 p.

MEREDITH JUNIOR, W. R.; BRIDGE, R. R. Heterosis and gene action in cotton. Crop Science, Madison, v. 12, p. 304-310, 1972.

MEREDITH JUNIOR, W. R.; WELLS, R. Normal vs. okra leaf yield interactions in cotton. I. Performance of near-isogenic lines from bulk populations. Crop Science, Madison, v. 26, p. 219-222, 1986.

MILLER, P. A.; LEE, J. A. Heterosis and combining ability in varietal top crosses of upland cotton Gossypium hirsutum L. Crop Science, Madison, v. 4, p. 646-649, 1964.

MILLER, P. A.; WILLIAMS, J. C.; COMSTOCK, R. E. Estimates of genotypic and environmental variances and covariances in upland cotton and their implications in selection. Agronomy Journal, Madison, v. 50, p. 126131,1958 .

RAO, S. B. P. Utilization of hybrid vigor in cotton: problems and prospects. Indian Journal of Genetics and Plant Breeding, Calcutta, v. 28, p. 245-250, 1968.

SHULL, G. H. Beginnings of the heterosis concept. In: GOWER, J. W. (Ed.). Heterosis. Ames : Iowa State College Press, 1952. p. 14-48

SILVA, F. P. da; MELO, F. I. O; TÁVORA, F. J. A. F.; COSTA NETO, F. V. Okra leaf and normal cotton isolines with different backgrounds. Brazilian Journal of Genetics, Ribeirão Preto, v. 19, p. 453-457, 1996.

VIRUSPARKSHAPPA, K.; KATARI, B. H.; RAO, M. R. G. Genetic analysis of yield in upland cotton Gossypium hirsutum L. Mysore Journal of Agricultural Sciences, Bangalore, v. 12, p. 22-25, 1978.

WILSON, F. D.; GEORGE, B. W. Effects of okra leaf, frego bract and smoothleaf mutants on pink bollworm damage and agronomic properties of cotton. Crop Science, Madison, v. 22, p. 798-801, 1982.

YOUNG, E. F.; MURRAY, J. C. Heterosis and inbreeding depression in diploid and tetraploid cotton. Crop Science, Madison, v. 6, p. 436-438, 1966. 